\title{
Effects of Combined Pre-straining and Pre-aging on Natural Aging and Bakehardening Response of an Al-Mg-Si Alloy
}

\author{
Zhiqing ZHANG ${ }^{\dagger}$, Huanhuan XU, Sainan WU and Yin LIU \\ College of Materials Science and Engineering, Chongqing University, Chongqing 400030, China \\ [Manuscript received 07 December 2012, in revised form 16 January 2013] \\ (C) The Chinese Society for Metals and Springer-Verlag Berlin Heidelberg
}

\begin{abstract}
For a series of $\mathrm{Al}-0.34 \% \mathrm{Mg}-1.05 \% \mathrm{Si}-0.08 \% \mathrm{Cu}$ alloys, the effects of pre-treatment on natural aging, bake hardening response and plasticity were investigated using Vickers hardness test and tensile test. Differential scanning calorimetry (DSC) analysis was conducted to reveal corresponding precipitation mechanisms. The results showed that pre-straining and pre-aging alone couldn't completely suppress natural aging and improve bake hardening response simultaneously. The sensitivity of the pre-straining and pre-aging on the mechanical properties was evaluated. It was found that pre-aging was the main factor which greatly improved bake hardening response and pre-treatment had a weak influence on plasticity in pre-treated samples. DSC analysis showed that the dissolution trough of clusters disappeared in pre-treated samples, both $\beta^{\prime \prime}$ and $\beta^{\prime}$ precipitation peak shifted to lower temperature and were reduced in pre-strained and pre-aged samples. It was concluded that the formation of $\mathrm{Mg} / \mathrm{Si}$ clusters was replaced by the accelerated precipitation of $\beta^{\prime \prime}$ and $\beta^{\prime}$ phases, which caused the suppression of natural aging and the improvement of bake hardening response (BHR).
\end{abstract}

\section{KEY WORDS: Pre-aging; Pre-straining; Aluminum alloy; Natural aging; Bake hardening response; Mechanical properties}

\section{Introduction}

With the continuing drive of weight reduction in the automobile industry, the 6xxx series Al-MgSi alloys have emerged as the most promising agehardenable body sheet material. These alloys offer a very attractive strength level obtained by artificial aging during the automotive paint bake cycle ${ }^{[1-3]}$.

The strengthening of Al-Mg-Si alloys in automotive applications is realized through a precipitation hardening process. However, the holding time in the paint bake process is usually not long enough and always leaves the alloy in an underaged condition. In addition, for most Al-Mg-Si alloys, the hardening response during artificial aging is adversely affected by natural aging, i.e. the practically unavoidable delay between solution treatment and artificial aging ${ }^{[4-6]}$. Hence, the microstructure of as-delivered sheet must

\footnotetext{
† Corresponding author. Assoc. Prof.; Tel: +86 23 65111547; Fax:+86 23 65106407; E-mail address: zqzhang@cqu.edu.cn (Zhiqing ZHANG)
}

DOI: $10.1007 / \mathrm{s} 40195-012-0239-5$ be modified to avoid any hardening during storage and improve bake hardening response (BHR) simultaneously.

Many studies have been devoted in recent years to counteract the adverse effect of natural aging and improve BHR during paint bake treatment. According to Dutta and Allen ${ }^{[7]}$, the precipitation sequence in $\mathrm{Al}-\mathrm{Mg}-\mathrm{Si}$ alloys is solute clusters $\rightarrow$ G.P. zones $($ spherical $) \rightarrow \beta^{\prime \prime} \quad$ (needle, $\left.\mathrm{Mg}_{5} \mathrm{Si}_{6}\right) \rightarrow \beta^{\prime}(\mathrm{rod}) \rightarrow$ $\beta\left(\mathrm{Mg}_{2} \mathrm{Si}\right)$. And it is well known that the $\beta^{\prime \prime}$ phase greatly contributes to the BHR in this alloy system ${ }^{[8]}$. Pre-aging, which is the most common practice to create clusters and enhance the formation of the $\beta^{\prime \prime}$ phase because of the continuous transformation into the $\beta^{\prime \prime}$ phase during the paint baking, is effective in reducing the detrimental effects of natural aging ${ }^{[9-11]}$. It was reported that an introduction of deformation as part of the thermal mechanical process could also improve the aging response of Al-Mg-Si alloys ${ }^{[12,13]}$. Precipitation kinetics have been observed to slow down in the deformed samples at low aging temperatures, due to the progressive annihilation of quenched-in 
vacancies on dislocations and then avoid clustering at room temperature ${ }^{[14]}$. Previous work has also shown that pre-straining accelerates precipitation at high temperatures because of decreased activation energy for precipitate nucleation and growth. Thus, the presence of dislocation generally results in an overall acceleration of the strengthening in $6 \mathrm{xxx}$ alloys ${ }^{[15]}$. A new pre-treatment process based on a combination of pre-straining and pre-aging has been developed in recent research ${ }^{[16-17]}$. In this process the pre-aging is usually performed at a low temperature, i.e., $70{ }^{\circ} \mathrm{C}$ for a short time.

Though pre-straining and pre-aging can both affect the natural aging and mechanical properties during the paint bake treatment, the sensitivity of the pre-straining and pre-aging has not been systematically and quantitatively investigated in the open literature. Elongation is a very important mechanical property which can influence the formability of Al$\mathrm{Mg}-\mathrm{Si}$ sheets after paint bake treatment. Unfortunately, less attention has been put on it in previous work. The goal of the present study is to find out if a combination of pre-straining and high temperature pre-aging, $170{ }^{\circ} \mathrm{C}$, could better retard the natural aging and improve the BHR of an Al-Mg-Si alloy without risking its plasticity. The sensitivity of pre-straining and pre-aging on natural aging and mechanical property during paint bake treatment will be analyzed in the present work.

\section{Experimental Procedure}

The $6 \mathrm{xxx}$ series alloy used in this study contained $0.34 \mathrm{Mg}, 1.05 \mathrm{Si}, 0.08 \mathrm{Cu}, 0.18 \mathrm{Fe}, 0.01 \mathrm{Mn}$ and $\mathrm{Al}$ bal. (wt.\%). The alloy ingot was homogenized and hotand cold-rolled to the final thickness of $1.2 \mathrm{~mm}$. The sheet was solution treated at $550{ }^{\circ} \mathrm{C}$ for $30 \mathrm{~min}$, and then quenched in water to room temperature. prestrained and pre-aged samples were pre-strained in tension by $2 \%$ and $5 \%$ shortly (within $5 \mathrm{~min}$ ) after the solution treatment and were pre-aged at $170^{\circ} \mathrm{C}$ for 3, 5 and $10 \mathrm{~min}$, respectively. Several sheet specimens were processed without pre-straining and preaging for the sake of comparison. Samples were designated as $\mathrm{PS}_{x}-\mathrm{PA}_{y}, x \%$ means the pre-straining strain, $y$ means the pre-aging time $(\min )$ at $170{ }^{\circ} \mathrm{C}$. $\mathrm{PS}_{x}-\mathrm{PA}_{0}$ means the sample had been pre-strained for $x \%$ and had not been pre-aged. $\mathrm{PS}_{0}-\mathrm{PA}_{y}$ means the sample had not been pre-strained and had been pre-aged for $y$ min. All samples were held at room temperature for $240 \mathrm{~h}$ (nature aging) before the final paint bake treatment. A simulated paint bake treatment refers to an artificial aging at $180{ }^{\circ} \mathrm{C}$ for $30 \mathrm{~min}$. The fabrication sequence of various treatments and corresponding sample names are shown in Fig. 1.

Since Al-Mg-Si sheets did not experience any plastic deformation during natural aging, microhardness was usually used to evaluate the strength evolution. The microhardness was tested in present work using a MH-5L microhardness tester which was produced by Shanghai Evrone Precision Instrument Co. Ltd. with a load of $5 \mathrm{~N}$ and a dwell time of $15 \mathrm{~s}$. The $0.2 \%$ offset yield strength (YS), ultimate tensile strength (UTS) and elongation were determined before and after the paint bake treatment using an SHIMADZU AG-X10KN computer controlled test machine with a gauge length of $25 \mathrm{~mm}$. The tests were performed at room temperature (R.T.) under uniaxial tensile loading with an initial strain rate of $0.025 \mathrm{~min}^{-1}$. Differential scanning calorimetry (DSC) analysis of the samples was employed to reveal the mechanism responsible for the changes of the mechanical properties using a METTLER-1100LF system, the samples were protected with flowing argon at a heating rate of $10{ }^{\circ} \mathrm{C} / \mathrm{min}$.

\section{Results and Discussion}

\subsection{The suppression of natural aging}

The microhardness change caused by the nature aging $\left(\Delta H V_{\text {na }}=H V_{\text {na }}-H V_{\text {pa }}\right)$ between the sample after nature aging for chosen time $\left(H V_{\text {na }}\right)$ and the sample before nature aging $\left(H V_{\mathrm{pa}}\right)$ are shown in Fig. 2. The microhardness of the $\mathrm{PS}_{0}-\mathrm{PA}_{0}$ before nature aging was (47.71 \pm 0.82$) \mathrm{HV}$ and increased by 23.09, 26.71 and $26.67 \mathrm{HV}$ after natural aging for 24, 96 and $240 \mathrm{~h}$ respectively. The microhardness curve of this sample during nature aging exhibited two stages. It increased very quickly for the first $24 \mathrm{~h}$ and reached its peak at $96 \mathrm{~h}$, then experienced a gentle increase during the last $120 \mathrm{~h}$. The microhardness curve of $2 \%$

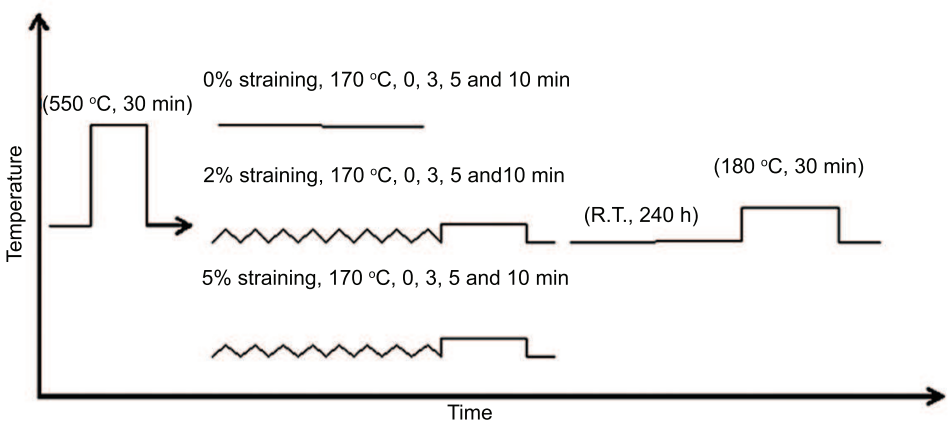

Fig. 1 Schematic diagram of various treatments for the Al-Mg-Si alloy (R.T. is room temperature) 

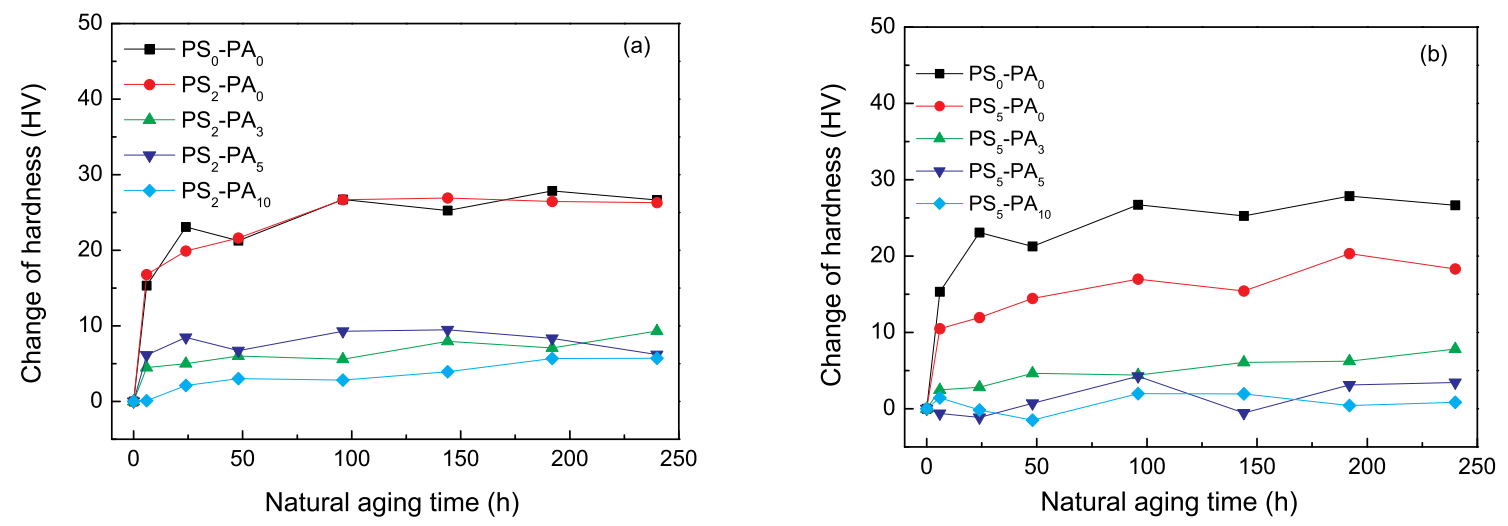

Fig. 2 The microhardness change of the specimens without or with $2 \%$ (a) and $5 \%$ (b) pre-straining and $0,3,5,10 \mathrm{~min}$ pre-aging at $170^{\circ} \mathrm{C}$ before paint bake treatment

pre-strained sample showed similar behavior to that of $\mathrm{PS}_{0}-\mathrm{PA}_{0}$. It is implied that the $2 \%$ pre-straining did not successfully suppress the strong natural aging. The microhardness change curve of the $2 \%$ prestrained and 3 min pre-aged sample reached its peak at $24 \mathrm{~h}$ and then kept very stable. It was also observed that the time to the peak hardness $(24 \mathrm{~h})$ in this sample was shortened compared to those ( $96 \mathrm{~h}$ ) of $\mathrm{PS}_{0}-\mathrm{PA}_{0}$ and $\mathrm{PS}_{2}-\mathrm{PA}_{0}$. The strong natural aging was successfully suppressed when pre-aging $\left(170{ }^{\circ} \mathrm{C}\right.$ for 3 , 5 and $10 \mathrm{~min}$ ) was introduced in $2 \%$ pre-strained samples (Fig. 2(a)). Suppression of the natural aging was also evidenced by microhardness measurements of $5 \%$ pre-strained and pre-aged samples (Fig. 2(b)). These results clearly indicated that the natural aging was not successfully retarded in the samples without any pre-treatment $\left(\mathrm{PS}_{0}-\mathrm{PA}_{0}\right)$, or $2 \%$ and $5 \%$ pre-strained alone samples $\left(\mathrm{PS}_{2}-\mathrm{PA}_{0}\right.$ and $\left.\mathrm{PS}_{5}-\mathrm{PA}_{0}\right)$.

The microhardness changes of the samples caused by nature aging and pre-treatment $\left(\Delta H V_{\mathrm{pt}}\right)$ are summarized in Fig. 3. As it shown in Fig. 3, the microhardness changes caused by pre-treatment increased with higher pre-straining level and longer pre-aging time. While the microhardness changes caused by natural aging decreased with higher prestraining level and longer pre-aging time. The minimum $\Delta H V_{\text {na }}$ was found in $\mathrm{PS}_{5}-\mathrm{PA}_{10}$ which had the highest pre-straining level and longest pre-aging time. Smaller $\Delta H V_{\text {na }}$ mean better suppression of natural aging, so it was reasonably concluded that prestraining and pre-aging alone had limited effect on the suppression of natural aging; a combination of the pre-straining and the pre-aging could suppress natural aging more effectively; higher pre-straining level combined with longer pre-aging time could cause stronger suppression effect.

\subsection{The improvement of bake hardening response}

The yield strength changes caused by bake hardening $\left(\Delta \mathrm{YS}_{\mathrm{BH}}\right)$ of non-pretreated and pre-strained alone samples were very low $\left(\mathrm{PS}_{0}-\mathrm{PA}_{0}, \mathrm{PS}_{2}-\mathrm{PA}_{0}, \mathrm{PS}_{5}-\mathrm{PA}_{0}\right)$,

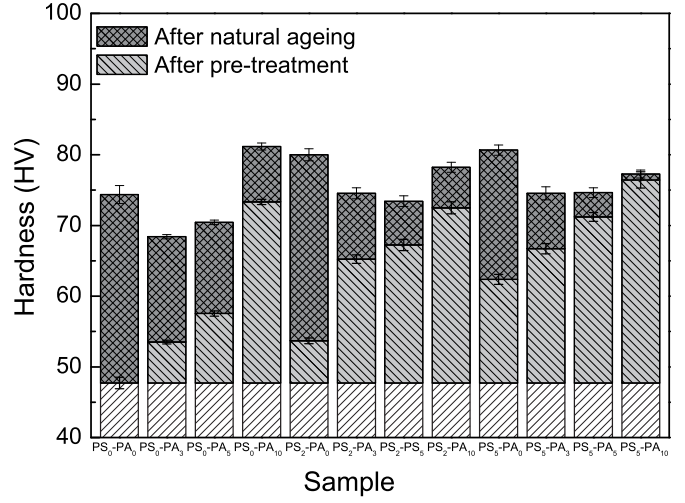

Fig. 3 Comparison of the hardness changes caused by pre-treatment and natural aging of samples pretreated with various conditions

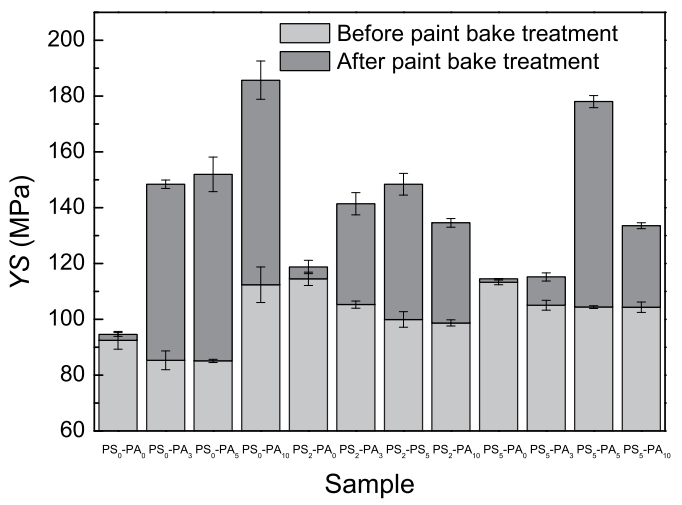

Fig. 4 Comparison of the YS changes (BHR) of samples pre-treated with various conditions

as shown in Fig. 4. The $\triangle \mathrm{YS}_{\mathrm{BH}}$ was much higher in pre-aged alone $\left(\mathrm{PS}_{0}-\mathrm{PA}_{3}, \mathrm{PS}_{0}-\mathrm{PA}_{5}, \mathrm{PS}_{0}-\mathrm{PA}_{10}\right)$ samples. The biggest $\triangle \mathrm{YS}_{\mathrm{BH}}$ in pre-strained + pre-aged samples was found in PS5-PA5 which was slightly higher than that of $\mathrm{PS}_{0}-\mathrm{PA}_{3}, \mathrm{PS}_{0}-\mathrm{PA}_{5}$, and $\mathrm{PS}_{0^{-}}$ $\mathrm{PA}_{10}$. Based on the $\Delta \mathrm{YS}_{\mathrm{BH}}$ above, it could be concluded that pre-straining alone had limited effect on $\mathrm{BHR}$ in this alloy; high temperature pre-aging could 
cause strong BHR; a combination of pre-straining and pre-aging did not obviously improve BHR.

The YS, UTS, elongation before and after paint bake of all samples were summarized in Table 1 . It should be noted that the initial elongation before paint bake of all the samples was very close; the difference between them was within $2 \%$. The changes of elongation of all pre-strained + pre-aged samples were smaller than 3\%. According to the elongation changes above, it was fair to conclude that elongation as a measure of plasticity was insensitive to the combined pre-treatments in the present alloy. Suppression of natural aging and improvement of BHR could be obtained without a large reduction in elongation. It is can be concluded from Table 1, that pre-aging has significant influence on $\Delta \mathrm{YS}$, while pre-aging and pre-straining have weak influence on $\Delta$ elongation. It indicates that the BHR is more sensitive to pre-aging than pre-straining.

\subsection{DSC Analysis}

DSC analysis was carried out to study the precipitation behavior of samples before natural aging. The G.P. (I) zone and $\beta^{\prime \prime}$ peaks were weakened, and the $\beta^{\prime \prime}$ peak shifted to lower temperature with increasing preaging time in DSC curves of all pre-aged alone samples (Fig. 5(a)). Thus we concluded that it meant more $\beta^{\prime \prime}$ nuclei formed during pre-aging and the precipitation of $\beta^{\prime \prime}$ phase was accelerated by high temperature preaging. Compared with the samples processed without pre-straining, both the exothermic peaks of $\mathrm{PS}_{2}-\mathrm{PA}_{0}$ near 150 and $220{ }^{\circ} \mathrm{C}$ were shifted to lower temperature in the DSC curve without decreasing their sizes (Fig. 5(b)). The shifts of precipitation peaks have been proven to be the acceleration of formation of $\beta^{\prime \prime}$ nuclei phases (G.P. (I) zones) and precipitation of $\beta^{\prime \prime}$ phase ${ }^{[18-20]}$. No precipitation peak change also indicated that no G.P. (I) zones or $\beta^{\prime \prime}$ phases formed during $2 \%$ pre-straining. The exothermic peak related to the formation of $\beta^{\prime \prime}$ nuclei phase expanded wider and two dissolution troughs, which can be observed around 80 and $180{ }^{\circ} \mathrm{C}$ were correspond to the dissolution of clusters and $\beta^{\prime \prime}$ nuclei phase respectively, weakened with increasing pre-aging time in $2 \%$ prestrained + pre-aged samples. Smaller G.P. (I) zone and $\beta^{\prime \prime}$ peak, during DSC heating indicated that part of the precipitation responsible for these exothermic peaks had taken place during pre-aging. The size of the $\beta^{\prime \prime}$ peak was reduced further and was shifted to lower temperature with increasing pre-aging time. The formation of $\beta^{\prime \prime}$ nuclei during pre-aging apparently reduced the supersaturation of the matrix, thus effectively suppressing the formation of clusters during natural aging. The $\beta^{\prime \prime}$ nuclei phase grew readily to become coherent $\beta^{\prime \prime}$ precipitation during the paint bake cycle, giving a considerable increase in strength $^{[21]}$. Similar changes in the DSC curves of the $5 \%$ pre-strained samples pre-aged for various times were found (Fig. 5(c)), but the G.P. (I) zone peak and dissolution troughs were more obviously reduced with higher pre-straining level. The smaller $\beta^{\prime \prime}$ peak during DSC heating in T4P temper was linked to the formation and growth of stable G.P. (I) zones which reduced the capacity to form clusters during natural aging. Thus, the suppression of natural aging and the effect of bake hardening were more prominent in pre-strained + pre-aged samples.

Based on the $\Delta H V_{\text {na }}$ during natural aging, YS increments after paint bake, and changes in DSC curves of all samples, it can be found that pre-straining alone accelerated the formation of G.P. (I) zone and $\beta^{\prime \prime}$ phase but did not change their intensities. Therefore

Table 1 Mechanical properties and paint bake response of samples with various pre-treatments

\begin{tabular}{|c|c|c|c|c|c|c|}
\hline \multirow[t]{2}{*}{ Sample } & \multicolumn{3}{|c|}{ Before/after paint bake } & \multicolumn{3}{|c|}{ Paint bake response } \\
\hline & YS (MPa) & UTS (MPa) & Elongation (\%) & $\Delta \mathrm{YS}(\mathrm{MPa})$ & $\Delta \mathrm{UTS}(\mathrm{MPa})$ & $\Delta$ Elongation $(\%)$ \\
\hline $\mathrm{PS}_{0}-\mathrm{PA}_{0}$ & $92.48 / 94.60$ & $172.58 / 185.03$ & $26.00 / 26.40$ & 2.12 & 12.45 & 0.4 \\
\hline $\mathrm{PS}_{0}-\mathrm{PA}_{3}$ & $85.31 / 148.39$ & $163.75 / 192.12$ & $25.90 / 26.30$ & 63.08 & 28.37 & 0.4 \\
\hline $\mathrm{PS}_{0}-\mathrm{PA}_{5}$ & $85.11 / 151.93$ & $173.81 / 201.55$ & $25.95 / 25.35$ & 66.82 & 27.74 & -0.6 \\
\hline $\mathrm{PS}_{0}-\mathrm{PA}_{10}$ & $112.37 / 185.70$ & $178.04 / 219.92$ & $25.00 / 15.70$ & 73.33 & 41.88 & -9.3 \\
\hline $\mathrm{PS}_{2}-\mathrm{PA}_{0}$ & $114.50 / 118.77$ & $197.43 / 196.2$ & $25.33 / 25.80$ & 4.27 & -1.23 & 0.47 \\
\hline $\mathrm{PS}_{2}-\mathrm{PA}_{3}$ & $105.27 / 141.43$ & $191.01 / 203.79$ & $25.79 / 26.00$ & 36.16 & 12.78 & 0.21 \\
\hline $\mathrm{PS}_{2}-\mathrm{PA}_{5}$ & $99.95 / 148.40$ & $178.55 / 196.66$ & $25.68 / 26.15$ & 48.45 & 18.11 & 0.47 \\
\hline $\mathrm{PS}_{2}-\mathrm{PA}_{10}$ & $98.70 / 134.58$ & $172.33 / 197.83$ & $23.96 / 25.90$ & 35.88 & 25.5 & 1.94 \\
\hline $\mathrm{PS}_{5}-\mathrm{PA}_{0}$ & $113.27 / 114.53$ & $193.40 / 211.51$ & $26.05 / 26.25$ & 1.26 & 18.11 & 0.2 \\
\hline $\mathrm{PS}_{5}-\mathrm{PA}_{3}$ & $105.07 / 115.19$ & $176.16 / 189.25$ & $25.25 / 25.69$ & 10.12 & 13.09 & 0.44 \\
\hline $\mathrm{PS}_{5}-\mathrm{PA}_{5}$ & $104.39 / 178.02$ & $185.27 / 234.62$ & $26.66 / 24.66$ & 73.63 & 49.35 & -2.00 \\
\hline $\mathrm{PS}_{5-P A 10}$ & $104.31 / 133.57$ & $177.83 / 195.32$ & $25.18 / 24.35$ & 29.26 & 17.49 & -0.83 \\
\hline
\end{tabular}



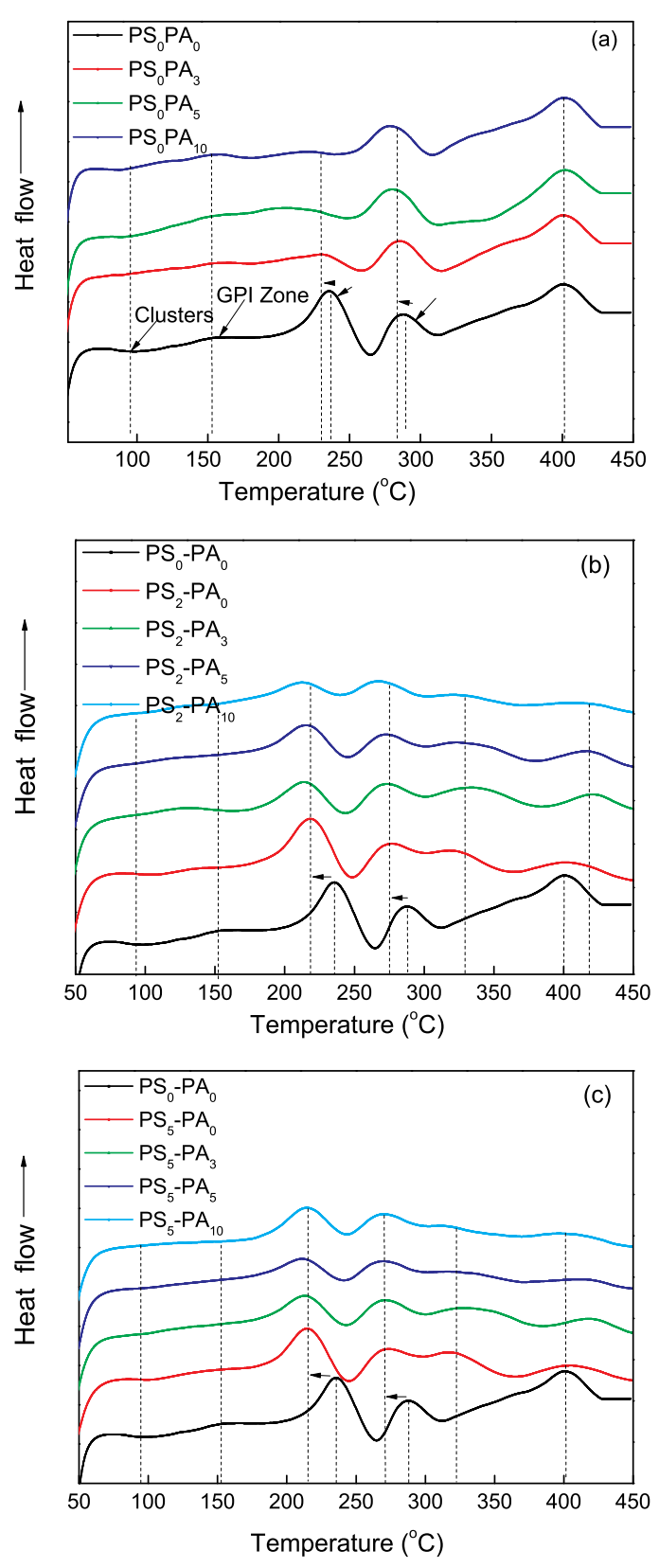

Fig. 5 DSC curves of samples without (a) and with $2 \%$ (b) and $5 \%$ (c) pre-straining, and $0,3,5$, and 10 min pre-aging at $170{ }^{\circ} \mathrm{C}$

pre-straining suppressed natural aging but did not clearly improve BHR. By contrast high temperature pre-aging accelerated the precipitation of G.P. (I) zones and $\beta^{\prime \prime}$ phase and greatly reduced their intensity, clearly suppressed natural aging and greatly improved BHR. The relationship between changes in the precipitation peaks and mechanical property behavior during natural aging and paint bake treatment agreed well with previous work ${ }^{[22]}$.

\section{Conclusions}

Based on the microhardness evolution, YS, UTS and elongation changes of all samples, it can be concluded that a combination of pre-straining and preaging can suppress natural aging more effectively than either alone. Higher pre-straining level combined with longer pre-aging time can lead to a better suppression effect. High temperature pre-aging can improve BHR without a large loss in plasticity; a combination of pre-straining and pre-aging do not obviously improve BHR. High temperature pre-aging accelerates the precipitation of G.P. (I) zone and $\beta^{\prime \prime}$ phase and greatly reduces their intensity, resulting in less natural aging and improves BHR. Suppression of natural aging and improvement of bake hardening are more sensitive to pre-aging than pre-straining in the present alloy.

\section{Acknowledgements}

This work was supported by the Fundamental Research Fund for the Central Universities (No.CDJZR10130018) and the Chongqing Science and Technology Commission (No.2011GZ0039). the authors also thank Prof. Robert E. Sanders Jr. for helpful discussion and language correction.

\section{REFERENCES}

[1] J. Buha, R.N. Lumley and A.G. Crosky, Metall. Mater. Trans. A 37 (2006) 3119.

[2] W.S. Miller, L. Zhuang, J. Bottema, A.J. Wittebrood, P. de Smet, A. Haszler and A. Vieregge, Mater. Sci. Eng. A 280 (2000) 37.

[3] V.L. Niranjani, K.C. Hari Kumar and V. Subramanya Sarma, Mater. Sci. Eng. A. 515 (2009) 169.

[4] S. Kleiner, C.H. Henkel and P. Schulz, Aluminium 77 (2001) 185.

[5] M. Torsæter, H.S. Hasting, W. Lefebvre, C.D. Marioara, J.C. Walmsley and S.J. Andersen, Appl. Phys. 108 (2010) 073527.

[6] S. Esmaeili, D.J. Lloyd and W.J. Poole, Acta Mater. 12 (2003) 3467.

[7] I. Dutta, S.M. Allen, J. Mater. Sci. 10 (1991) 323.

[8] A.K. Gupta, D.J. Lloyd and S.A. Court, Mater. Sci. Eng. 316 (2001) 11.

[9] Y. Birol, Mater. Sci. Eng. A. 391 (2005) 175.

[10] S. Pogatscher, H. Antrekowitsch, H. Leitner, T. Ebner and P.J. Uggowitzer, Acta Mater. 59 (2011) 3352.

[11] L.Z. He, H.T. Zhang, J.Z. Cui, J. Mater. Sci. Technol. 26 (2010) 141.

[12] G.K. Quainoo, J. Mater. Sci. 39 (2004) 4841.

[13] J. Dutkiewicz and L. Litynska, Mater. Sci. Eng. A 324 (2002) 239.

[14] S. Ceresara and P. Fiorini, Mater. Sci. Eng. 10 (1972) 205.

[15] P. Gomiero, A. Reeves, A. Pierre, F. Bley, F. Livet and H. Vichery, in: the 4th Int. Conf. on Aluminum Alloys, Georgia Institute of Technology, Atlanta, U.S., Sept.11-16 1994.

[16] C.H. Shen, J. Mater. Sci. Technol. 27 (2011) 205.

[17] M. Tetsuya and T. Yasuo, Mater. Trans. 51 (2010) 325.

[18] L. Zhen and S.B. Kang, Mater. Lett. 37 (1998) 349.

[19] W.F. Miao and D.E. Laughlin, Scr. Mater. 40 (1999) 873.

[20] C.S.T. Chang and J. Banhart, Metall. Mater. Trans. A 42 (2011) 1960.

[21] Y. Birol, Scr. Mater. 54 (2006) 2003.

[22] Y. Birol and M. Karlik, Mater. Sci. Technol. 21 (2005) 153. 